\title{
Antimicrobial Susceptibility and Prevalence of bla and $q n r$ Genes in Salmonella Enterica Isolated from Slaughtered Pork
}

\section{Alyzza Marie B. Calayag}

University of the Philippines Diliman

Kenneth W. Widmer

United States Department of Agriculture

Windell L. Rivera ( $\nabla$ wlrivera@science.upd.edu.ph )

University of the Philippines Diliman https://orcid.org/0000-0002-4659-6132

Research article

Keywords: antimicrobial resistance, bla, extended-spectrum $\beta$-lactamase, qnr, Salmonella enterica

Posted Date: January 13th, 2021

DOI: https://doi.org/10.21203/rs.3.rs-143023/v1

License: (c) (i) This work is licensed under a Creative Commons Attribution 4.0 International License.

Read Full License 


\section{Abstract}

Background: Salmonella enterica is known as one of the most common foodborne pathogens worldwide. While salmonellosis is usually self-limiting, severe infections may require antimicrobial therapy. However, increasing resistance of Salmonella to antimicrobials, particularly fluoroquinolones and cephalosporins, is of utmost concern. The present study aimed to investigate the antimicrobial susceptibility of $S$. enterica isolated from pork, the major contributor in Philippine livestock production.

Results: Our results show that $61.2 \%$ of the isolates carried antimicrobial resistance genes qnrS and bla $a_{T E M}$. While qnrA $(12.9 \%)$ and $q n r B(39.3 \%)$ were found less frequently, co-carriage of bla $a_{\text {TEM }}$ and one to three qnr subtypes was observed in $45.5 \%$ of the isolates. Co-carriage of $b / a_{T E M}$ and $b / a_{C T X-M}$ was also observed in $3.9 \%$ of the isolates. Antimicrobial susceptibility testing revealed that majority of the isolates were non-susceptible to ampicillin and trimethoprim/sulfamethoxazole, and $13.5 \%$ of the isolates were multidrug-resistant.

Conclusions: High prevalence rates of $S$. enterica carrying antimicrobial resistance genes (ARG), specifically the presence of isolates co-carrying resistance to both ß-lactams and fluoroquinolones, raise a concern on antimicrobial use in the Philippine hog industry and on possible transmission of ARG to other bacteria.

\section{Background}

Salmonella infections, or salmonellosis, are commonly acquired through consumption of contaminated food of animal origin. In the Philippines, Salmonella enterica was shown to be the leading cause of foodborne disease outbreaks from 1995-2018 [1, 2]. While the disease is usually self-limiting, it may require antimicrobial therapy when the infection becomes invasive. The fluoroquinolone ciprofloxacin and the extended-spectrum cephalosporin (ESC) ceftriaxone are the current treatments of choice because the emergence of antimicrobial resistance (AMR) has rendered several drugs such as ampicillin, chloramphenicol, and trimethoprim/sulfamethoxazole obsolete in salmonellosis therapy [3, 4].

Resistance to ß-lactams, such as ESCs, is most commonly attributed to the bla genes of subtypes TEM, $\mathrm{SHV}$, and CTX-M which encode for ß-lactamases that hydrolyze the ß-lactam ring, thereby rendering the drug inactive $[5,6]$. In contrast to ß-lactam resistance, fluoroquinolone resistance is typically attributed to chromosomal mutations in the quinolone targets DNA gyrase and topoisomerase IV, and overexpression of efflux pumps that reduce drug accumulation [7]. However, plasmid-mediated quinolone resistance (PMQR), such as qnr genes, may also occur. These genes are broadly distributed worldwide and are commonly found in association with genes encoding for ß-lactamases [8-11]. Consequently, bla and qnr genes have been increasingly found in bacteria isolated from livestock animals [8, 9, 12-17]. If motile, resistance determinants may accelerate the spread of AMR when these are taken up by non-pathogenic or pathogenic bacteria alike. 
There is evidence that substantial use of antimicrobials in food-producing animals may drive the emergence of drug-resistant strains $[12,18,19]$. While the use of certain antimicrobials such as nitrofurans and chloramphenicol has been banned in livestock production in several parts of the world, AMR in agriculture remains a global challenge $[12,19]$. Monitoring AMR development in livestock and meat allows early detection of AMR emergence and prevalence [20] which can be used to design interventions to improve antimicrobial therapy and reduce resistance selection pressure [21,22]. This is generally accomplished by antimicrobial susceptibility testing (AST) and detection of antimicrobial resistance genes (ARG).

In the Philippines, pork makes up the majority of livestock production and amounts to a 3.8M USD industry [23]. The country's rapidly growing population is expected to further increase pork consumption and production. If left unchecked, AMR may lead to challenges in food production, food security, food safety, economic losses to the hog industry, and AMR spillover to the surrounding environment $[12,18$, 22]. Therefore, this study aimed to investigate the antimicrobial susceptibility and prevalence of $B$ lactamase-encoding genes ( $b / a_{C T X-M}, b / a_{S H V}$ and $\left.b / a_{T E M}\right)$ and plasmid-mediated quinolone resistance ( $q n r A, q n r B$, and $q n r S$ ) in S. enterica from slaughtered pork in Metro Manila, Philippines.

\section{Results}

A total of 178 isolates were analyzed in this study. Vitek ${ }^{\circledR} 2$ AST revealed that the isolates were generally resistant to ß-lactams, but susceptible to quinolones. A large number were non-susceptible to ampicillin (72.5\%) and trimethoprim/sulfamethoxazole (70.8\%). Non-susceptibility to key drugs, ceftazidime, ceftriaxone, and ciprofloxacin were observed in $8.4 \%, 7.9 \%, 15.7 \%$ of the isolates, respectively (Table 1 ). Multidrug resistance was observed in 24 (13.5\%) isolates; most of which were non-susceptible to four classes of antimicrobial agents (Table 2). One ESBL-producing isolate was also detected. 
Table 1

Non-susceptibility levels of $178 \mathrm{~S}$. enterica isolates against different antimicrobial agents. Antimicrobials are classified into categories based on the recommendations of Magiorakos et al. [24]. Non-susceptibility to non-ESCs, cephamycins, and aminoglycosides are not shown as these antimicrobial agents are not clinically effective, although they may appear active in vitro.

\begin{tabular}{|lll|}
\hline Class & Antimicrobial & $\begin{array}{l}\text { \% Non- } \\
\text { susceptibility }\end{array}$ \\
\hline Penicillin & Ampicillin & $71.9 \%(128)$ \\
\hline Penicillin / B-lactamase inhibitor & Amoxicillin / clavulanic acid & $10.1 \%(18)$ \\
\hline $\begin{array}{l}\text { Antipseudomonal penicillin / ß-lactamase } \\
\text { inhibitor }\end{array}$ & Piperacillin / tazobactam & $0.6 \%(1)$ \\
\hline Extended-spectrum cephalosporin & Ceftazidime & $8.4 \%(15)$ \\
\cline { 2 - 3 } & Ceftriaxone & $7.9 \%(14)$ \\
\hline Carbapanem & Ertapenem & $0.0 \%(0)$ \\
\cline { 2 - 3 } & Imipenem & $1.7 \%(3)$ \\
\cline { 2 - 3 } & Meropenem & $0.0 \%(0)$ \\
\hline Fluoroquinolone & Ciprofloxacin & $15.7 \%(28)$ \\
\hline Folate pathway inhibitor & $\begin{array}{l}\text { Trimethoprim / } \\
\text { sulfamethoxazole }\end{array}$ & $70.8 \%(126)$ \\
\hline
\end{tabular}


Table 2

Multidrug resistance patterns of 24 S. enterica isolates.

\begin{tabular}{ll} 
Number of $S$. enterica isolates & Multidrug resistance pattern \\
\hline 1 & Pen, Pen/BI, APen/BI, ESC, Flu \\
14 & Pen, Pen/BI, FPI, ESC \\
1 & Pen, Pen/BI, FPI, Car \\
1 & Pen, Pen/BI, FPI, Flu \\
6 & Pen, FPI, Flu \\
\hline 1 & Pen, Pen/BI, FPI
\end{tabular}

aPen, penicillin; Pen/BI, penicillin/ß-lactamase inhibitor; APen/BI; antipseudomonal penicillin / ßlactamase inhibitor; ESC, extended-spectrum cephalosporin; Flu, fluoroquinolone; FPI, folate pathway inhibitor; Car, carbapenem.

Polymerase chain reaction (PCR) assays targeting bla genes revealed that $61.2 \%$ and $5.1 \%$ of the isolates were harboring the $b / a_{T E M}$ and $b / a_{C T X-M}$ genes, respectively. No isolate carried $b / a_{S H V}$. CTX-M variant typing revealed that $6 / 9 b_{C T X}{ }^{-}$carrying isolates carried $b / a_{C T X-M-1}$, and $3 / 9$ carried bla ${ }_{C T X-M-2}$. Co-carriage of $b / a_{C T X-M}$ (four under the CTX-M-1 group, three under the CTX-M-2 group) and $b / a_{T E M}$ was observed in seven isolates. For qnr genes, $12.9 \%, 39.3 \%$, and $61.2 \%$ were harboring the $q n r A$, $q n r B$, and $q n r S$ genes, respectively. Co-carriage of $b / a_{T E M}$ and one to three $q n r$ subtypes were found in $45.5 \%$ of the isolates (Fig. 1).

\section{Discussion}

Since it has been established that ampicillin and trimethoprim/sulfamethoxazole have become obsolete in salmonellosis therapy, high non-susceptibility rates to these antimicrobials were expected. In many countries, aminopenicillins, which include ampicillin, trimethoprim, sulfamethoxazole, and trimethoprim/sulfonamide combinations are among the most frequently used antimicrobials in livestock production [12, 26]. These antimicrobials are generally administered in all phases of hog production [26]. In this study, non-susceptibilities to ampicillin and trimethoprim/sulfamethoxazole were observed in $71.9 \%$ and $70.8 \%$ of $S$. enterica, respectively. Phongaran et al. [13] reported that $69.0 \%$ of Salmonella isolated from hogs in Thailand were resistant to ampicillin. However, in this study, only $35.7 \%$ were resistant to trimethoprim/sulfamethoxazole. One study conducted among hogs in Vietnam reported that $36.7 \%$ of Salmonella isolates were resistant to trimethoprim/sulfamethoxazole and only $41.3 \%$ to ampicillin [27]. On the other hand, low rates of resistance ( $<5 \%)$ to ESC and ciprofloxacin were reported in both studies $[13,27]$, while this present study reported rates which were slightly higher $(<10 \%)$.

In this study, multidrug resistance was observed in $13.5 \%$ of $S$. enterica isolates. Reports of (multidrugresistant) MDR Salmonella isolated from hogs in other Southeast Asian countries are higher (30-40\%) $(13,27)$. In other countries, even higher rates $(70-80 \%)$ of MDR Salmonella isolated from pork and the pork production chain were observed $[15,28]$. Out of 24 MDR S. enterica isolates in the present study, 15 
and 8 were non-susceptible to ESC and fluoroquinolones, respectively, the current drug options in treating salmonellosis. Multidrug resistance is a challenge as it narrows down the options for antimicrobial therapy.

Majority of studies on bla genes and livestock animals in Southeast Asian countries are focused on $E$. coli in which bla $a_{T E M}$ and $b / a_{C T X-M}$ are the most frequently identified bla genes [12]. In Salmonella, bla ${ }_{T E M}$ appears to be the most common. In India, Lalruatdiki et al. [14] observed that $30 \%$ of Salmonella isolated from a pig population were carrying bla $a_{T E M}$ and $10 \%$ were carrying bla $a_{C T X-M}$. Co-carriage of $b / a_{C T X-M}$ and bla $a_{T E M}$ has also been observed in extended-spectrum ß-lactamase (ESBL)-producing Salmonella from pigs $[14,29]$. In the present study, co-carriage of bla $a_{T E M}$ and $b / a_{C T X-M}$ was found in seven (3.9\%) isolates. However, none of these isolates were ESBL-producing which could suggest that these are only carrier of silent bla genes. The only ESBL-producing Salmonella in this study was carrying only bla bla $_{T E M}$ in the study possibly confer only broad-spectrum ß-lactam resistance considering the high rates of non-susceptibility to ampicillin, its presence in combination with other resistance determinants could render an isolate multidrug-resistant.

We report in this study that $71.3 \%$ of $S$. enterica isolates harbored PMQR. The genes qnrA, qnrB, and qnrS were observed in $12.9 \%, 39.3 \%$, and $61.2 \%$ of the isolates, respectively. While Qnr proteins offer only low resistance against quinolones, the high incidence of PMQR may be a cause for concern since it has been shown to broaden the mutant selection window in bacteria [7]. Lin et al. [16] demonstrated that ciprofloxacin resistance conferred by PMQR is even comparable to that of quinolone target mutations. Prevalence rates of qnrgenes appear to vary among samples and geographical locations. Cameron-Veas et al. [15] reported that $15 \%$ of $S$. enterica isolated from a pork production chain in Brazil were carrying $q n r B$, and none were carrying $q n r A$ and $q n r S$. A separate study in China reported the prevalence of $q n r A$ (0\%), qnrB (16\%), and qnrS (66\%) [16] in foodborne Salmonella. In Thailand and in Laos, Sinwat et al. [17] found only $1-8 \%$ of $S$. enterica isolated from pork to be carrying the same qnr genes. This highlights the importance of a national surveillance of ARG since it appears individual countries seem to have different prevalence rates.

Several studies have also reported the association of qnrgenes with bla genes. One MDR Salmonella isolated from a piglet in Spain was carrying both $q n r B$ and bla ${ }_{C T X}-M$. Moawad et al. [8] found that $33 \%$ of Salmonella from poultry and beef in Egypt were carrying qnrgenes and either $b / a_{C T X-M^{p}} b / a_{T E M}$ or both. Whether qnr and bla genes reside within the same plasmid was not confirmed in either of the studies. However, Penha Filho et al. [9] recently isolated Salmonella from poultry in Brazil which carried both $b_{C T X-M-2}$ and $q n r B$ in the same plasmid. In clinical isolates of S. enterica, E. coli, and K. pneumoniae, qnrgenes have also been found within the same plasmid as that of $b / a_{T E M}$ or $b / a_{C T X-M}[10,11]$. In the

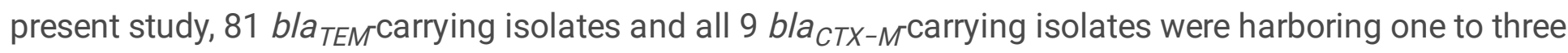
qnr subtypes.

\section{Conclusions}


The increasing prevalence of MDR Salmonella in livestock animals has been widely reported $[13,15,27$, $28]$ and is mainly attributed to the inappropriate use of antimicrobial agents in veterinary medicine [18, 19]. We report that $89.4 \%$ of $S$. enterica isolated from slaughtered pork were non-susceptible to at least one antimicrobial agent and $13.5 \%$ were MDR. Majority of the isolates were also harboring $b / a_{T E M}$ which possibly encode broad-spectrum ß-lactamases, and qnrS which could facilitate emergence of mutations that target quinolone resistance. While worldwide AMR surveillance has allowed the determination of the evolution of resistance, national surveillance will allow countries to create policies that would fit their needs. Generation of local information on AMR and antimicrobial consumption in the veterinary and agricultural sectors will allow the development of relevant approaches to tackle AMR [21, 22]. This is highly important for low- and middle-income countries (LMICs) as strategies proven effective to work in developed countries may not be suitable for LMICs. Attention to AMR in the agricultural sector began in the Philippines only recently, and further surveillance is necessary to identify emerging resistant $S$. enterica in the pork production chain.

\section{Methods}

\section{Sample collection}

The study population consisted of freshly slaughtered hogs from six abattoirs across the different districts of Metro Manila, Philippines. Informed consent was obtained from the Philippine National Meat Inspection Service, hence, ethics approval was waived for this particular study. Animal slaughter and evisceration were performed according to national regulations. Informed consent was also obtained from veterinarians in charge of the abattoirs, and farm owners for sample collection. Tissue samples from hog tonsils and jejunum were collected post-slaughter and under the supervision of a veterinarian. Sample collection was performed as previously described [30]. Briefly, tissues were collected from each hog upon evisceration using sterile forceps and scissors, and then immediately transferred into sterile bags. All samples were kept chilled upon collection and during transport, and were immediately processed in the laboratory.

\section{Bacterial Isolation And Identification}

Bacteria were first enriched prior to isolation as previously described [30]. Briefly, $25 \mathrm{~g}$ of each sample was transferred to $225 \mathrm{~mL}$ buffered peptone water (BPW), and incubated overnight at $35^{\circ} \mathrm{C}$. Afterwards, $100 \mu \mathrm{L}$ of pre-enriched bacterial culture in BPW was inoculated into $10 \mathrm{~mL}$ Rappaport-Vassiliadis broth $(\mathrm{RVB})$, and then incubated overnight at $42^{\circ} \mathrm{C}$ for selective enrichment of $S$. enterica. RVB cultures were then inoculated onto brilliant green agar (BGA) and xylose lysine deoxycholate agar (XLD), and then incubated overnight at $35^{\circ} \mathrm{C}$ for isolation. Presumptive $S$. enterica were then inoculated onto nutrient agar and incubated overnight at $35^{\circ} \mathrm{C}$ for subsequent total DNA extraction. 
Total DNA was extracted by harvesting colonies using a sterile $1 \mu \mathrm{L}$ loop and suspending these in $100 \mu \mathrm{L}$ TE buffer (10 mM Tris, $1 \mathrm{mM}$ EDTA at pH 8.0). The suspension was boiled for $10 \mathrm{~min}$, and pelleted at $6000 \mathrm{rpm}$ for $5 \mathrm{~min}$. The supernatant was collected and then stored at $-20^{\circ} \mathrm{C}$ until use. These DNA extracts were used in both PCR-based identification of $S$. enterica and detection of ARG.

Each PCR reaction for $S$. enterica identification contained $2 \mu \mathrm{L}$ DNA, 10 pmol each of forward and reverse primers, and HiPi PCR Premix (Elpis Biotech, Daejeon, South Korea) in a final volume of $20 \mu \mathrm{L}$.

Amplification of a 244-bp region in the species-specific invA gene was performed as previously described [31]. PCR products were subsequently analyzed via capillary electrophoresis. Salmonella enterica KCTC 2421 was used as a positive control.

\section{Antimicrobial susceptibility testing}

Vitek ${ }^{\circledR} 2$ AST was used to generate the antimicrobial susceptibility profiles of the isolates. It automatically classifies isolates into susceptible, intermediate, or resistant to a particular antimicrobial agent based on the latest breakpoints provided by the Clinical and Laboratory Standards Institute (CLSI). Multidrug resistance was defined as non-susceptibility to at least one antimicrobial agent in three or more antimicrobial categories as recommended by Magiorakos et al. [24].

Inoculum preparation for the automated AST was followed as previously described [30]. Vitek® 2 ASTN261 cards were used which contain 15 antimicrobials including amikacin, amoxicillin/clavulanate, ampicillin, cefepime, cefoxitin, ceftazidime, ceftriaxone, ciprofloxacin, colistin, ertapenem, gentamicin, imipenem, meropenem, piperacillin/tazobactam, and trimethoprim/sulfamethoxazole. Colistin was not tested because there are currently no CLSI breakpoints available for Salmonella spp. Each test run was accompanied with antimicrobial susceptibility tests for Escherichia coli ATCC 25922 (negative control for ESBL test) and Klebsiella pneumoniae ATCC 600703 (positive control for ESBL test).

\section{Detection of bla and qnrgenes}

S. enterica isolates were screened for ß-lactamase-encoding genes ( $b / a_{C T X-M} b / a_{S H V}$ and $\left.b / a_{T E M}\right)$ and quinolone resistance genes ( $q n r A, q n r B$, and $q n r S$ ) using monoplex PCR assays. The primers used are listed in Table 3. For bla genes, each reaction contained $2 \mu \mathrm{L}$ DNA, 10 pmol each of forward and reverse primers, and AccuPower ${ }^{\circledR}$ PCR Premix or Maxime PCR Premix ( $i$-StarTaq $\left.{ }^{\mathrm{TM}} \mathrm{GH}\right)$ in a final volume of $20 \mu \mathrm{L}$. PCR was carried out under the following conditions: initial denaturation step at $95^{\circ} \mathrm{C}$ for $3 \mathrm{~min} ; 30$ cycles

of denaturation at $95{ }^{\circ} \mathrm{C}$ for $30 \mathrm{~s}$, annealing at $58^{\circ} \mathrm{C}$ for $b / a_{C T X-M,} 56^{\circ} \mathrm{C}$ for $b / a_{S H V}$, and $50{ }^{\circ} \mathrm{C}$ for $b / a_{T E M}$ for $30 \mathrm{~s}$, extension at $72^{\circ} \mathrm{C}$ for $1 \mathrm{~min}$; and a final extension step at $72^{\circ} \mathrm{C}$ for $10 \mathrm{~min}$. For qnr genes, each reaction contained $2 \mu \mathrm{L}$ DNA, 10 pmol each of forward and reverse primers, and $6.25 \mu \mathrm{L} \mathrm{GoTaq}{ }^{\circledR}$ Green Master Mix in a final volume of $12.5 \mu \mathrm{L}$. PCR was carried out under the following conditions: initial denaturation step at $95^{\circ} \mathrm{C}$ for $5 \mathrm{~min} ; 33$ cycles of denaturation at $95^{\circ} \mathrm{C}$ for $1 \mathrm{~min}$, annealing at $60^{\circ} \mathrm{C}$ for $1 \mathrm{~min}$, extension at $72{ }^{\circ} \mathrm{C}$ for $1 \mathrm{~min}$; and a final extension step at $72{ }^{\circ} \mathrm{C}$ for $10 \mathrm{~min}$. 
Table 3

Primers used in screening for antimicrobial resistance genes.

\begin{tabular}{|c|c|c|c|}
\hline Target gene & Nucleotide sequence $\left(5^{\prime}-3^{\prime}\right)$ & $\begin{array}{l}\text { Amplicon } \\
\text { length } \\
\text { (bp) }\end{array}$ & Reference \\
\hline \multirow[t]{2}{*}{$b l a_{S H V}$} & F: ATGCGTTATATTCGCCTGTG & 747 & [32] \\
\hline & R: TGCTTTGTTATTCGGGCCAA & & \\
\hline \multirow[t]{2}{*}{$b / a_{T E M}$} & F: TCGCCGCATACACTATTCTCAGAATGA & 445 & [5] \\
\hline & R: ACGCTCACCGGCTCCAGATTTAT & & \\
\hline \multirow[t]{2}{*}{ bla ${ }_{C T X-M}$} & F: ATGTGCAGYACCAGTAARGTKATGGC & 593 & [33] \\
\hline & R: TGGGTRAARTARGTSACCAGAAYCAGCGG & & \\
\hline \multirow{2}{*}{$b / a_{C T X-M-1}$} & F: AAAAATCACTGCGCCAGTTC & 415 & [34] \\
\hline & R: AGCTTATTCATCGCCACGTT & & \\
\hline \multirow[t]{2}{*}{$b^{\prime} a_{C T X-M-2}$} & F: CGATATCGTTGGTGGTRCCAT & 404 & [6] \\
\hline & R: CGTTAACGGCACGATGAC & & \\
\hline \multirow[t]{2}{*}{ bla $_{C T X-M-9}$} & F: CAAAGAGAGTGCAACGGATG & 205 & [34] \\
\hline & R: ATTGGAAAGCGTTCATCACC & & \\
\hline$b^{\prime} a_{C T X-M-8 / 25}$ & F: AACCCACGATGTGGGTAGC & & \\
\hline$b / a_{C T X-M-8}$ & R: TCGCGTTAAGCGGATGATGC & 666 & [34] \\
\hline bla ${ }_{C T X-M-25}$ & R: GCACGATGACATTCGGG & 327 & [34] \\
\hline \multirow[t]{2}{*}{$q n r A$} & F: AGAGGATTTCTCACGCCAGG & 580 & [35] \\
\hline & R: TGCCAGGCACAGATCTTGAC & & \\
\hline \multirow[t]{2}{*}{$q n r B$} & F: GGAATAGAAATTCGCCACTG & 264 & [36] \\
\hline & R: TTTGCTGTTCGCCAGTCGAA & & \\
\hline \multirow[t]{2}{*}{ qnrs } & F: GCAAGTTCATTGAACAGGGT & 428 & [35] \\
\hline & R: TCTAAACCGTCGAGTTCGGCG & & \\
\hline
\end{tabular}

S. enterica isolates carrying $b / a_{C T X-M}$ were subjected to further PCR assays to identify CTX-M variants. The primers used in CTX-M variant typing are listed in Table 3. Each reaction contained $2 \mu \mathrm{L}$ DNA, $10 \mathrm{pmol}$ each of forward and reverse primers, and $6.25 \mu \mathrm{L} \mathrm{GoTaq}{ }^{\circledR}$ Green Master Mix (Promega) in a final volume of $12.5 \mu \mathrm{L}$. Amplification was performed as previously described. [6]. 
Amplicons were analyzed in $1.5 \%$ agarose gels stained either with GelRed ${ }^{\text {TM }}$ Nucleic Acid Gel Stain or SYBR® Safe DNA Gel Stain (1:10,000). Amplicons were allowed to separate at $100 \mathrm{~V}$ for $20-30 \mathrm{~min}$, and then viewed in a gel documentation system. KAPA ${ }^{\text {TM }}$ Universal Ladder was used to estimate the molecular weights of the products.

\section{Abbreviations}

AMR - antimicrobial resistance

ARG - antimicrobial resistance gene

AST - antimicrobial susceptibility testing

BGA - brilliant green agar

CLSI - Clinical and Laboratory Standards Institute

ESBL - extended-spectrum $\beta$-lactamase

ESC - extended spectrum cephalosporin

LMICs - low- and middle-income countries

MDR Salmonella - multidrug-resistant Salmonella

PCR - polymerase chain reaction

PMQR - plasmid-mediated quinolone resistance

RVB - Rappaport-Vassiliadis broth

TE buffer - Tris-EDTA buffer

XLD - xylose lysine deoxycholate

\section{Declarations}

\section{Ethics approval and consent to participate}

Informed consent was obtained from the Philippine National Meat Inspection Service, hence, ethics approval was waived for this particular study. Animal slaughter and evisceration were performed according to national regulations. Informed consent was also obtained from veterinarians in charge of the abattoirs, and farm owners for sample collection. 
Not applicable.

\section{Availability of data and materials}

The datasets used and/or analyzed during the current study are available from the corresponding author on reasonable request.

\section{Competing interests}

The authors declare that they have no competing interests.

\section{Funding}

This study was supported by the Department of Agriculture-Biotechnology Program Office, Philippines (Project Code: DABIOTECH-R1808); the UNU \& GIST Joint Programme on Science and Technology for Sustainability, Gwangju Institute of Science and Technology, Korea; and the Office of the Vice Chancellor for Research and Development of the University of the Philippines Diliman through its Thesis and Dissertation Grant.

\section{Authors' contributions}

$A B C$ and WLR conceptualized the study. ABC performed experimental assays, data analysis, and made the first draft of the manuscript. KWW carried out data interpretation and troubleshooting of the assays. WLR and KWW made the necessary revisions before manuscript submission. All authors read and approved the final manuscript.

\section{Acknowledgement}

We thank Ms. Phyllis Anne Paclibare for her invaluable assistance in sample collection and processing.

\section{References}

1. Azanza MPV. Philippine foodborne-disease outbreaks (1995-2004). J Food Saf. 2006;26(1):92-102.

2. Azanza MPV, Membrebe BNQ, Sanchez RGR, Estilo EEC, Dollete UGM, Feliciano RJ, et al. Foodborne Disease Outbreaks in the Philippines (2005-2018). Philipp J Sci. 2019;148(2):317-36.

3. Britto CD, Wong VK, Dougan G, Pollard AJ. A systematic review of antimicrobial resistance in Salmonella enterica serovar Typhi, the etiological agent of typhoid. PLoS Negl Trop Dis [Internet]. 2018 Oct;12(10):e0006779-e0006779. Available from: https://pubmed.ncbi.nlm.nih.gov/30307935 DOI: 10.1371/journal.pntd.0006779.

4. Gut AM, Vasiljevic T, Yeager T, Donkor ON. Salmonella infection-prevention and treatment by antibiotics and probiotic yeasts: a review. Microbiology. 2018;164(11):1327-44.

5. Monstein H-J, Östholm-Balkhed Å, Nilsson MV, Nilsson M, Dornbusch K, Nilsson LE. Multiplex PCR amplification assay for the detection of blaSHV, blaTEM and blaCTX-M genes in Enterobacteriaceae. 
APMIS [Internet]. 2007 Dec;115(12):1400-8. Available from:

https://pubmed.ncbi.nlm.nih.gov/18184411/ DOI: 10.1111/j.1600-0463.2007.00722.x.

6. Dallenne C, Da Costa A, Decré D, Favier C, Arlet G. Development of a set of multiplex PCR assays for the detection of genes encoding important $\beta$-lactamases in Enterobacteriaceae. J Antimicrob Chemother [Internet]. 2010 Mar;65(3):490-5. Available from:

https://academic.oup.com/jac/article/65/3/490/748889 DOI: 10.1093/jac/dkp498.

7. Jacoby GA. Mechanisms of resistance to quinolones. Clin Infect Dis [Internet]. 2005 Jul;41(Supplement_2):S120-6. Available from:

https://academic.oup.com/cid/article/41/Supplement_2/S120/307501 DOI: 10.1086/428052.

8. Moawad AA, Hotzel H, Awad O, Tomaso H, Neubauer H, Hafez HM, et al. Occurrence of Salmonella enterica and Escherichia coli in raw chicken and beef meat in northern Egypt and dissemination of their antibiotic resistance markers. Gut Pathog [Internet]. 2017;9(1):57. Available from: https://www.ncbi.nlm.nih.gov/pmc/articles/PMC5648511/ DOI: 10.1186/s13099-017-0206-9.

9. Penha Filho RAC, Ferreira JC, Kanashiro AMI, Berchieri Junior A, Darini AL da C. Emergent multidrugresistant nontyphoidal Salmonella serovars isolated from poultry in Brazil coharboring blaCTX-M-2 and $q n r B$ or blaCMY-2 in large plasmids. Diagn Microbiol Infect Dis [Internet]. 2019;95(1):93-8. Available from: http://www.sciencedirect.com/science/article/pii/S0732889318305443 DOI: 10.1016/j.diagmicrobio.2019.04.003.

10. Cheung TKM, Chu YW, Chu MY, Ma CH, Yung RWH, Kam KM. Plasmid-mediated resistance to ciprofloxacin and cefotaxime in clinical isolates of Salmonella enterica serotype Enteritidis in Hong Kong. J Antimicrob Chemother [Internet]. 2005 Sep;56(3):586-9. Available from: https://academic.oup.com/jac/article/56/3/586/691005 DOI: 10.1093/jac/dki250.

11. Gutierrez B, Herrera-Leon S, Escudero JA, Hidalgo L, Gonzalez-Sanz R, Arroyo M, et al. Novel genetic environment of qnrB2 associated with TEM-1 and SHV-12 on pB1004, an IncHI2 plasmid, in Salmonella Bredeney BB1047 from Spain. J Antimicrob Chemother [Internet]. 2009 Dec;64(6):13346. Available from: https://academic.oup.com/jac/article/64/6/1334/740715 DOI: 10.1093/jac/dkp340.

12. Nhung NT, Cuong NV, Thwaites G, Carrique-Mas J. Antimicrobial usage and antimicrobial resistance in animal production in Southeast Asia: a review. Antibiotics. 2016;5(4):37.

13. Phongaran D, Khang-Air S, Angkititrakul S. Molecular epidemiology and antimicrobial resistance of Salmonella isolates from broilers and pigs in Thailand. Vet World [Internet]. 2019 Aug;12(8):1311-8. Available from: https://pubmed.ncbi.nIm.nih.gov/31641313 DOI: 10.14202/vetworld.2019.13111318.

14. Lalruatdiki A, Dutta TK, Roychoudhury P, Subudhi PK. Extended-spectrum $\beta$-lactamases producing multidrug resistance Escherichia coli, Salmonella and Klebsiella pneumoniae in pig population of Assam and Meghalaya, India. Vet World [Internet]. 2018 Jun;11(6):868-73. Available from: https://pubmed.ncbi.nlm.nih.gov/30034183 DOI: 10.14202/vetworld.2018.868-873. 
15. Cameron-Veas K, Fraile L, Napp S, Garrido V, Grilló MJ, Migura-Garcia L. Multidrug resistant Salmonella enterica isolated from conventional pig farms using antimicrobial agents in preventative medicine programmes. Vet J [Internet]. 2018 Apr;234:36-42. Available from: http://www.sciencedirect.com/science/article/pii/S1090023318300339 DOI: 10.1016/j.tvjl.2018.02.002.

16. Lin D, Chen K, Chan EW-C, Chen S. Increasing prevalence of ciprofloxacin-resistant food-borne Salmonella strains harboring multiple PMQR elements but not target gene mutations. Sci Rep. 2015;5(1):1-8.

17. Sinwat N, Angkittitrakul S, Coulson KF, Pilapil FMIR, Meunsene D, Chuanchuen R. High prevalence and molecular characteristics of multidrug-resistant Salmonella in pigs, pork and humans in Thailand and Laos provinces. J Med Microbiol. 2016;65(10):1182-93.

18. Khachatourians GG. Agricultural use of antibiotics and the evolution and transfer of antibioticresistant bacteria. Can Med Assoc J. 1998;159(9):1129-36.

19. Barton MD. Impact of antibiotic use in the swine industry. Curr Opin Microbiol [Internet]. 2014;19(Supplement C):9-15. Available from: http://www.sciencedirect.com/science/article/pii/S1369527414000642 DOI: 10.1016/j.mib.2014.05.017.

20. Reller LB, Weinstein M, Jorgensen JH, Ferraro MJ. Antimicrobial susceptibility testing: a review of general principles and contemporary practices. Clin Infect Dis [Internet]. 2009 Dec;49(11):1749-55. Available from: https://academic.oup.com/cid/article/49/11/1749/344384 DOI: 10.1086/647952.

21. Kerr JR. Antibiotic treatment and susceptibility testing. J Clin Pathol [Internet]. 2005 Aug;58(8):786787. Available from: https://jcp.bmj.com/content/58/8/786.full DOI: 10.1136/jcp.2005.030411.

22. Kakkar M, Chatterjee P, Chauhan AS, Grace D, Lindahl J, Beeche A, et al. Antimicrobial resistance in South East Asia: time to ask the right questions. Glob Health Action [Internet]. 2018 May;11(1):1483637. Available from: https://www.tandfonline.com/doi/full/10.1080/16549716.2018.1483637 DOI: 10.1080/16549716.2018.1483637.

23. Philippine Statistics Authority. Database: agriculture, forestry, fisheries [Internet]. [cited 2020 Oct 16]. Available from: http://openstat.psa.gov.ph/.

24. Magiorakos A-P, Srinivasan A, Carey RB, Carmeli Y, Falagas ME, Giske CG, et al. Multidrug-resistant, extensively drug-resistant and pandrug-resistant bacteria: an international expert proposal for interim standard definitions for acquired resistance. Clin Microbiol Infect [Internet]. 2012 Mar;18(3):268-81. Available from: https://www.clinicalmicrobiologyandinfection.com/article/S1198-743X(14)616323/fulltext DOI: 10.1111/j.1469-0691.2011.03570.x.

25. Lex A, Gehlenborg N, Strobelt H, Vuillemot R, Pfister H. UpSet: visualization of intersecting sets. IEEE Trans Vis Comput Graph. 2014;20(12):1983-92.

26. Lekagul A, Tangcharoensathien V, Yeung S. Patterns of antibiotic use in global pig production: a systematic review. Vet Anim Sci [Internet]. 2019 Jun;7:100058. Available from: 
http://www.sciencedirect.com/science/article/pii/S2451943X18302473 DOI:

10.1016/j.vas.2019.100058.

27. Tu LTP, Hoang NVM, Cuong NV, Campbell J, Bryant JE, Hoa NT, et al. High levels of contamination and antimicrobial-resistant non-typhoidal Salmonella serovars on pig and poultry farms in the Mekong Delta of Vietnam. Epidemiol Infect [Internet]. 2015 Mar;143(14):3074-86. Available from: https://www.ncbi.nlm.nih.gov/pmc/articles/PMC4595858/ DOI: 10.1017/S0950268815000102.

28. Viana C, Sereno MJ, Pegoraro K, Yamatogi RS, Call DR, dos Santos Bersot L, et al. Distribution, diversity, virulence genotypes and antibiotic resistance for Salmonella isolated from a Brazilian pork production chain. Int J Food Microbiol [Internet]. 2019 Nov;310:108310. Available from: http://www.sciencedirect.com/science/article/pii/S0168160519302417 DOI: 10.1016/j.ijfoodmicro.2019.108310.

29. Trongjit S, Angkititrakul S, Tuttle RE, Poungseree J, Padungtod P, Chuanchuen R. Prevalence and antimicrobial resistance in Salmonella enterica isolated from broiler chickens, pigs and meat products in Thailand-Cambodia border provinces. Microbiol Immunol [Internet]. 2017 Jan;61(1):2333. Available from: https://onlinelibrary.wiley.com/doi/full/10.1111/1348-0421.12462 DOI: 10.1111/1348-0421.12462.

30. Calayag AMB, Paclibare PAP, Santos PDM, Bautista CAC, Rivera WL. Molecular characterization and antimicrobial resistance of Salmonella enterica from swine slaughtered in two different types of Philippine abattoir. Food Microbiol. 2017;65:51-6.

31. Ng KCS, Rivera WL. Multiplex PCR-based serogrouping and serotyping of Salmonella enterica from tonsil and jejunum with jejunal lymph nodes of slaughtered swine in Metro Manila, Philippines. $\mathrm{J}$ Food Prot. 2015;78(5):873-80.

32. Paterson DL, Hujer KM, Hujer AM, Yeiser B, Bonomo MD, Rice LB, et al. Extended-spectrum $\beta$ lactamases in Klebsiella pneumoniae bloodstream isolates from seven countries: dominance and widespread prevalence of SHV-and CTX-M-type $\beta$-lactamases. Antimicrob Agents Chemother [Internet]. 2003 Nov;47(11):3554-60. Available from:

http://aac.asm.org/content/47/11/3554.abstract DOI: 10.1128/AAC.47.11.3554-3560.2003.

33. Boyd DA, Tyler S, Christianson S, McGeer A, Muller MP, Willey BM, et al. Complete nucleotide sequence of a 92-kilobase plasmid harboring the CTX-M-15 extended-spectrum beta-lactamase involved in an outbreak in long-term-care facilities in Toronto, Canada. Antimicrob Agents Chemother [Internet]. 2004 Oct;48(10):3758-64. Available from: http://aac.asm.org/content/48/10/3758.abstract DOI: 10.1128/AAC.48.10.3758-3764.2004.

34. Woodford N, Fagan EJ, Ellington MJ. Multiplex PCR for rapid detection of genes encoding CTX-M extended-spectrum $\beta$-lactamases. J Antimicrob Chemother [Internet]. 2006 Jan;57(1):154-5. Available from: https://academic.oup.com/jac/article/57/1/154/915084 DOl: 10.1093/jac/dki412.

35. Cattoir V, Poirel L, Rotimi V, Soussy C-J, Nordmann P. Multiplex PCR for detection of plasmidmediated quinolone resistance qnr genes in ESBL-producing enterobacterial isolates. J Antimicrob 
Chemother [Internet]. 2007 Aug;60(2):394-7. Available from:

https://academic.oup.com/jac/article/60/2/394/714189 DOl: 10.1093/jac/dkm204.

36. Cattoir V, Weill F-X, Poirel L, Fabre L, Soussy C-J, Nordmann P. Prevalence of qnrgenes in Salmonella in France. J Antimicrob Chemother [Internet]. 2007 Apr;59(4):751-4. Available from: https://academic.oup.com/jac/article/59/4/751/676141 DOI: 10.1093/jac/dkl547.

\section{Figures}

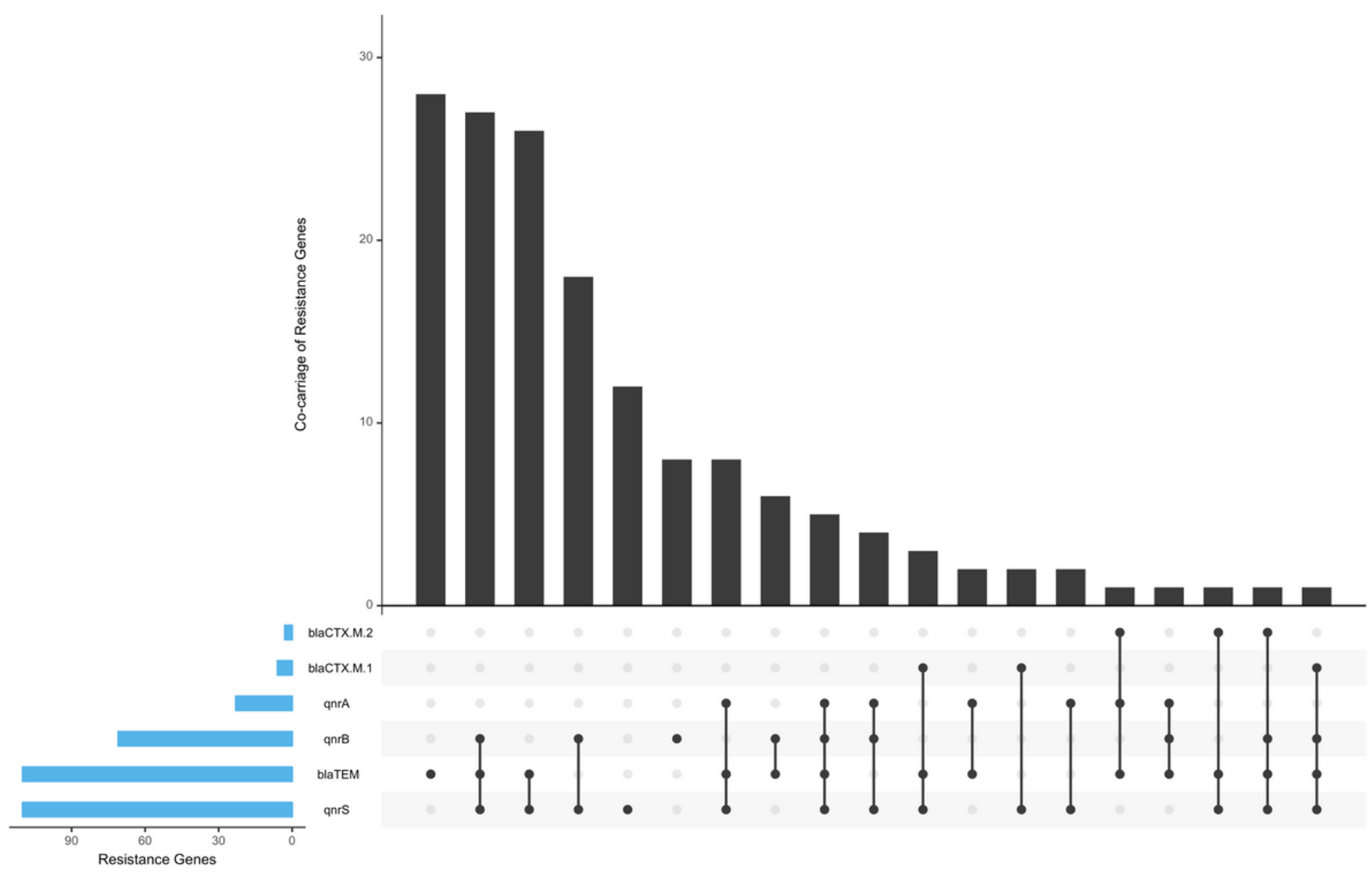

Figure 1

S. enterica isolates carrying resistance genes. Horizontal bar graphs show the total number of isolates carrying a particular ARG; vertical bar graphs show the number of isolates carrying one or more ARG. Figure was generated using UpSetR [25]. 